\title{
Manejo sanitário em confinamentos
}

Rafahel Carvalho de Souza;, Rogério Carvalho Souza, Guilherme Lobato Menezes

Pontifícia Universidade Católica de Minas (PUC Minas), Betim, MG, Brasil

*Autor correspondente

e-mail: rafahelsouza@pucminas.br

\section{Resumo}

A população mundial está em constante crescimento, assim como a demanda de alimentos de qualidade. Nesse contexto, confinar bovinos de corte é uma estratégia para potencializar a produção de carne bovina. Por esse motivo, nos últimos anos o número de confinamentos tem aumentado no Brasil. Produzir muito em pouco espaço e tempo tem sido um grande desafio gerencial e sanitário. Desta forma, foi objetivo do presente estudo avaliar o manejo sanitário que tem sido adotado nos confinamentos atuais através da realização de um questionário semiestruturado. Os dados utilizados foram coletados entre janeiro e abril de 2016 e foram provenientes de 20 confinamentos da região de Minas Gerais e São Paulo, sendo um confinamento em Minas Gerais e nove em São Paulo. Os questionários, aplicados mediante autorização prévia do responsável pelo confinamento, solicitavam informações quanto ao tipo de protocolo sanitário, rotina de ronda sanitária, critérios para vermifugação, principais causas de mortalidade e forma como era feito o diagnóstico de animais que morreram. A capacidade estática dos confinamentos variou de 2 a 53 mil cabeças, com uma média de 13.540 mil animais por confinamento, sendo a área por boi de $10 \mathrm{~m}^{2} \mathrm{a} 15 \mathrm{~m}^{2} /$ animal. A metade $(5 ; 50 \%)$ dos confinamentos avaliados possuia sistema de aspersão de água para evitar poeira. Dos 10 confinamentos entrevistados, sete $(70 \%)$ realizavam quatro tratos nas secas e cinco tratos nas águas, dois (20\%) realizavam cinco tratos durante todo o ano, e um (10\%) realizava oito tratos durante o ano todo. Todos os confinamentos realizavam ronda sanitária diária, sendo que os animais identificados com anormalidades eram tratados e identificados de acordo com o protocolo da propriedade. Caso fosse necessário, eram encaminhados ao curral de enfermaria para maiores cuidados. Quando questionados em relação ao exame de contagem de ovos por grama de fezes (OPG) e de oocitos por grama de fezes (OOPG) foi observado que nenhum dos confinamentos realizava tais exames. As principais causas de mortalidade relatadas foram pneumonia, acidose, clostridioses e timpanismo. A pneumonia foi responsável 
por aproximadamente $80 \%$ das mortes nos confinamentos entrevistados. Nos confinamentos avaliados, 90\% realizavam diagnóstico baseado somente em sinais clínicos. Apenas 30\% realizavam diagnóstico baseado em sinais clínicos e necropsia, e nenhum deles realizava exames complementares. Apesar dos confinamentos possuírem tecnologias avançadas em outras áreas, como a nutrição, as questões sanitárias ainda são negligenciadas. 